\title{
Comparison of Bipolar TURP and Monopolar TURP Patients Who Underwent Surgery Due to Benign Prostatic Hyperplasia
}

\author{
(D) Mustafa Erkoç¹, (D) Hüseyin Beşiroğlu² \\ ${ }_{1}^{1}$ Beylikdüzü State Hospital, Clinic of Urology, istanbul, Turkey \\ ${ }^{2}$ Çatalca ilyas Çokay State Hospital, Clinic of Urology, Istanbul, Turkey
}

\section{Abstract}

Objective: Benign prostatic hyperplasia (BPH) is the one of the most common disease in the world. Transurethral resection of prostate (TURP) is the gold standard procedure in BPH surgery. So TURP methods are important. The aim of our study is to compare bipolar (B) TURP and monopolar (M) TURP methods.

Methods: In our study is included 120 patients who underwent TURP due to BPH. The patients were examined in two groups of 60 people. M-TURP was applied to one group while B-TURP was applied to the other group. Patients International Prostate Symptom score (IPSS), uroflowmetry (Qmax), hemoglobin loss, postoperative catheterization time, hospital stay, TUR syndrome and $6^{\text {th }}$ month postoperative urethral stricture parameters were investigated. In the statistical analysis, chi-square, Student's t-test and Wilcoxon test were performed.

Results: Two groups were analyzed separately and compared. In IPSS, Qmax, hospital stay, hemoglobin loss parameters there was no significantly difference between two groups. The duration of postoperative catheterization and development of urethral stricture at postoperative $6^{\text {th }}$ months found statistically significant; in the M-TURP group, more stricture development and longer catheterization time were observed $(p<0.05)$. At the same time TURP syndrome was observed in 2 patients in M-TURP group and TUR syndrome was not observed in B-TURP group $(p<0,05)$.

Conclusion: B-TURP and M-TURP groups were compared. The results of both groups were similar. Only in the B-TURP group, in terms of the probability of stricture and the development of the TUR syndrome was more advantageous than M-TURP. In conclusion, B-TURP is more reliable method than M-TURP and both methods can be reliably applied in BPH surgery.

Keywords: Bipolar TURP, BPH, monopolar TURP, TURP

\section{INTRODUCTION}

Benign prostatic hyperplasia (BPH) and lower urinary tract symptoms (LUTS) due to BPH are among the most common diseases in the world. It is estimated that 1.1 billion people were affected by symptoms associated with BPH in 2018 (1). In the US, BPH is seen in $80 \%$ of men above 70 years of age and $15-60 \%$ of men over 40 years of age. Surgical treatment is performed to $25 \%$ of all men $(2,3)$.

Amid the high prevalence of BPH in population, both medical and surgical treatments of BPH are widely used. In the last 20 years, more technologically advanced and minimally invasive methods with fewer complications than the transurethral resection of prostate (TURP) like high intensity focused ultrasound, laser vaporization, and laser enucleation were described. Although these methods have lower complication rates than TURP, their efficiencies have not surpassed that of TURP, and they have higher rates of reoperation. Therefore, TURP is still the goldstandard treatment for BPH lower than 80 cc in volume $(4,5)$.

TURP also has considerable complications. Monopolar (M) TURP, which was the first method used in previous studies, had severe complications such as postoperative early and late bleeding, postoperative urinary retention, TUR syndrome, urethral stricture 
in the late period, and erectile dysfunction (5). Therefore, new methods have been developed for TURP, and bipolar methods were started to be used nearly as commonly as unipolar TURP. It is seen as a candidate to replace M-TURP in the future (6). Therefore, many previous trials have compared $\mathrm{M}$ and bipolar (B) TURP methods.

The aim of this study was to compare operation room efficiencies and complication rates of unipolar and B-TURP methods. The results of this study may help to choose the method to be used for patients in the future.

\section{METHODS}

This study was performed after approval by Okmeydani Training and Research Hospital Ethics Committee (approval date: 17.11.2015; No: 358). This trial included 120 patients who had prostatic surgery due to BPH at Beylikduzu State Hospital between September 2016 and June 2018. Patients with acute prostatitis, patients using 5 alpha reductase inhibitors due to their effects on prostate specific antigen (PSA), patients with urethral strictures, patients who previously undergone prostate biopsies, patients with neurogenic bladders, and patients with previous lower urinary tractus operations were excluded. In this trial, the patients were classified into two equal groups and M-TURP and B-TURP, which are two different methods of goldstandard TURP for BPH treatment. Before the operation, digital rectal examination, urinary and transrectal ultrasonography, PSA, uroflowmetry, postvoiding residual volume measurement, and prostate measurement were performed routinely to investigate LUTS. Urine biochemistry and culture were also routinely performed to exclude infection. International Prostate Symptom score (IPSS) was used to measure symptom score of the patients. According to this scale, the patients were divided into three groups as no-mild (0-7), moderate (8-19), and severe (20-35).

Storz resectoscope (Karl Storz GmbH, Tuttlingen, Germany) with 26 French (F) device was used in the M-TURP group and storz bipolar resectoscope (Karl Storz GmbH, Tuttlingen, Germany) with $26 \mathrm{~F}$ device was used in the B-TURP group. BOWA ARC 400 device was used as cautery for both of the groups. For the M-TURP group, 120-watt cautery force was used for cutting mode, and 80 -watt cautery force was used for coagulation mode. The same values were used for B-TURP to achieve standardization. These two groups were compared according to the development of postoperative urethral stricture, postoperative hemoglobin loss, postoperative catheterization; development of TUR syndrome, and postoperative Qmax and IPSS.

\section{Statistical Analysis}

SPSS 15.0 package program (SPSS for Windows, 15.0, SPSS Inc., Chicago, Illinois, USA) was used for statistical analyses. To evaluate quantitative data, paired-sample Student's t-test was used for comparisons that meet normal distribution criteria, and the Wilcoxon test was used for those that don't meet criteria. The chi-square test was used to evaluate qualitative data. A p value lower than 0.05 was accepted as significant.

\section{RESULTS}

This study included 120 patients. These patients were divided into two 60-patient groups. The demographic data of the patients were similar. Mean ages and preoperative IPSS, PSA, uroflowmetry, and hemoglobin values of the patients are shown in Table 1.

Postoperative IPSS, Qmax, hemoglobin loss, postoperative catheterization time, hospital stay duration, TUR syndrome, and stricture at postoperative $6^{\text {th }}$ month were evaluated separately in the M-TURP and the B-TURP groups. Statistical analysis revealed no significant difference in IPSS, uroflowmetry, duration of hospital stay, and hemoglobin loss parameters $(p>0.05)$. Postoperative catheterization duration and urethral stricture development at postoperative $6^{\text {th }}$ month were statistically significant. In the M-TURP group, the duration of catheterization was longer, and stricture development at postoperative $6^{\text {th }}$ month was more frequent $(p<0.05)$. Two patients in the M-TURP group developed TUR syndrome, while no TUR syndrome was observed in the B-TURP group $(p<0.05)$. Isotonic irrigation fluid was used in the B-TURP group while irrigation fluid with mannitol, which is known to increase TUR syndrome, was used in the M-TURP group. Detailed data for all parameters are shown in Table 2.

\section{DISCUSSION}

Surgeries for BPH are among the most frequently performed surgeries in the world. Treatment guidelines define recurrent urinary infections, resistant hematuria, and impairment of

\begin{tabular}{|l|l|l|}
\hline \multicolumn{3}{|l|}{ Table 1. Demographic data of the patients } \\
\hline Parameters $\mathbf{n = 1 2 0}$ & M-TURP & B-TURP \\
\hline Age (mean \pm SD) & $63.95 \pm 7.7$ & $64.82 \pm 8.1$ \\
\hline Prostate volume & $70.3 \pm 13.2$ & $68.4 \pm 14.8$ \\
\hline PSA & $3.3 \pm 0.4$ & $3.2 \pm 0.3$ \\
\hline IPSS & $22.8 \pm 4.7$ & $22.6 \pm 4.9$ \\
\hline Uroflowmetry (Qmax) & $7.3 \pm 3.2$ & $7.8 \pm 3.4$ \\
\hline Hemoglobin & $13.8 \pm 1.2$ & $13.4 \pm 1.3$ \\
\hline SD: Stand
\end{tabular}

SD: Standard deviation, PSA: Prostate specific antigen, IPSS: International Prostate Symptom score, M-TURP: Monopolar transurethral resection of prostate, B-TURP: Bipolar transurethral resection of prostate 
renal functions as the absolute indications for surgery. In other patients, symptoms of the patients should be assessed, and treatment should be chosen according to the severity of symptoms (7). TURP is the most commonly applied surgical method for BPH. According to the European Urology Association guidelines complications of TURP include incontinence (1.8\%), bladder neck contraction (4.7\%), urethral stricture (3.8\%), TUR syndrome (1.1\%), blood transfusion requirement (8.4\%), retrograde ejaculation (65.4\%), and erectile dysfunction (6.5\%) (8).

Many trials have compared monopolar and bipolar surgeries in terms of functional results, complications, and irrigation fluids. In a meta-analysis by Cornu et al. (9), which included 69 of these trials, no difference could be found in 1-year results for IPSS, life quality parameters, Qmax in uroflowmeter, postvoiding residual volume, and prostate volume. In the same study, no difference could also be detected for operation lengths and the rate of infection after operations. In this meta-analysis, there was no TUR syndrome in patients operated with B-TURP (9). Also, B-TURP groups were better in terms of duration of hospitalization and catheterization, the number of transfusions, retention secondary to clots, and postoperative retention (9). Similar to this meta-analysis, Ahyai et al. (10) and Mamoulakis et al. (11) found similar functional results and postoperative complications at $12^{\text {th }}$ month in their meta-analysis.

In contrast to these meta-analysis, in their case series including 1000 patients, Puppo et al. (12) found that urethral stricture is more frequent with M-TURP (2-10\%) compared with B-TURP compared with M-TURP (1\%) which is consistent with the working mechanisms of these two methods. Several other studies which compared M and B-TURP yielded conflicting results (12-14).

Erectile dysfunction is also a frequently investigated parameter in trials comparing B-TURP and M-TURP. No significant difference could be found between the two methods (15).

\begin{tabular}{|l|l|l|l|}
\hline \multicolumn{4}{|l|}{ Table 2. Comparisons of several posoperative parameters } \\
\hline Parameters $\mathbf{n = 1 2 0}$ & M-TURP (60) & B-TURP (60) & p value \\
\hline IPSS & $6.4 \pm 1.3$ & $6.3 \pm 1.6$ & 0.62 \\
\hline Postop Uroflowmetry (Qmax) & $19.8 \pm 3.6$ & $20.3 \pm 3.9$ & 0.38 \\
\hline $\begin{array}{l}\text { Postop duration of } \\
\text { catheterization }\end{array}$ & $3.5 \pm 0.9$ & $3.1 \pm 0.8$ & 0.008 \\
\hline Hemoglobin loss & $2.2 \pm 0.6$ & $2.0 \pm 0.7$ & 0.15 \\
\hline Duration of hospital stay & $4.4 \pm 0.8$ & $4.2 \pm 0.9$ & 0.098 \\
\hline Urethral stricture & 7 & 3 & 0.006 \\
\hline TUR syndrome & 2 & 0 & 0.009 \\
\hline $\begin{array}{l}\text { IPSS: International Prostate Symptom score, TUR: Transurethral resection, M-TURP: } \\
\text { Monopolar transurethral resection of prostate, B-TURP: Bipolar transurethral } \\
\text { resection of prostate }\end{array}$
\end{tabular}

Hemoglobin values, postoperative electrolyte values, and TUR syndrome were also evaluated in several trials comparing M-TURP and B-TURP. Karadeniz et al. (16) couldn't find a statistically significant difference between the two methods for hemoglobin values but detected significant differences in postoperative 1 st-hour and 24th-hour sodium levels. Also, Michielsen et al. (17) detected significant differences in postoperative sodium levels. In both of these studies, postoperative TUR syndrome wasn't detected in any cases treated with B-TURP. In our study, Qmax and IPSS parameters were similar between B and M-TURP. Urethral stricture rate was better in the B-TURP group than the M-TURP group, similar to the meta-analysis findings. No difference was detected in length of hospital stay, or hemoglobin value. The duration of catheterization was longer in the M-TURP group. No TUR syndrome was detected in the B-TURP group, while 2 cases of TUR syndrome were detected in the M-TURP group. Small sample size was a limitation of our study.

\section{CONCLUSION}

In conclusion, the results of $\mathrm{B}$ and M-TURP are generally similar. B-TURP was better only in TUR syndrome and stricture development and duration of catheterization. The complication rate was low. Both methods can be used safely in BPH surgery.

\section{Ethics}

Ethics Committee Approval: Okmeydani Training and Research Hospital Ethics Committee (approval date: 17.08.2016; No: 458). This trial included 120 patients who had prostatic surgery due to BPH at Beylikdüzü State Hospital between September 2016 and June 2018.

Informed Consent: Form was obtained from the patients.

Peer-review: Externally peer-reviewed.

\section{Authorship Contributions}

Surgical and Medical Practices: M.E., Concept: M.E., Design: M.E., Analysis or Interpretation: H.B., M.E., Literature Search: H.B., Writing: H.B.

Conflict of Interest: No conflict of interest was declared by the authors.

Financial Disclosure: The authors declared that this study received no financial support.

\section{REFERENCES}

1. Irwin DE, Kopp ZS, Agatep B, Milsom I, Abrams P. Worldwide prevalence estmitates of lower urinary tract symptoms, overactive bladder, urinary incontinence, and bladder outlet obstruction. BJU int 2011:108;1132-8. 
2. Parsons JK. Benign Prostatic Hyperplasia and Male Lower Urinary Tract Symptoms: Epidemiology and Risk Factors. Curr Bladder Dysfunct Rep 2010;5:212-8.

3. Mebust WK, Holtgrewe HL, Cockett AT, Peters PC. Transurethral prostatectomy; immediate and postoperative complications.A cooperative study of 13 participating institutions evaluating 3885 patients. J Urol 1989;141:243-7.

4. Başok E, Tokuç R. Benign Prostat Hiperplazisinde minimal invaziv yöntemler medikal tedavinin yerini alabilir mi? Üroonkoloji Bülteni Aralık 2009;38-43.

5. Reich 0 , Gratzke G, Stief CG. Techniques and long term results of surgical procedures for BPH. Eur Urol 2006;49:970-6.

6. Issa M. Technological Advances in transurethral resection of the prostate: Bipolar versus Monopolar TURP. J Endourol 2008;22:1587-95.

7. Chapple CR. The total approach in lower urinary tract symptoms/ benign prostatic hyperplasia (LUTS/BPH) management:introduction and conclusions. Eur Urol 2003;2:1-5.

8. Oelke M, Bachmann A, Descezaud A, Emberton M, Gravas S, Michel MC, et al. Managemet of lower urinary tract symptoms (LUTS). EAU Guidelines 2012;40-3.

9. Cornu JN, Ahyai S, Bachmann A, de la Rosette J, Gilling P, Gratzke C, et al. A systematic review and meta-analysis of functional outcomes and complications following transurethral procedures for lower urinary tract symptoms resulting benign prostatic obstruction;an update. Eur Urol 2015;67:1066-96.

10. Ahyai SA, Gilling P, Kaplan SA, Kuntz RM, Madersbacher S, Montorsi F, et al. Meta-analysis of functional outcomes and complications following transurethral procedures for lower urinary tract symptoms resulting from benign prostatic enlargement. Eur Urol 2010;58:384-97.
11. Mamoulakis C, De la Rosette JJ, Ubbink DT. Re; Burke et al.: systematic review and meta-analysis of transurethral resection of the prostate versus minimally invasiv procedures for the treatment of benign prostatic obstruction. Urology 2010;75:1015-22.

12. Puppo P, Bertolotto F, Introini C, Germinale F, Timossi L, Naselli A. Bipolar transurethral resection in saline (TUR-is):Outcome and complication rates after the first 1000 cases. J Endourol 2009;23:1145-9.

13. Ho HS, Yip SK, Lim KB, Fook S, Foo KT, Cheng CW. A prospective randomized study comparing monopolar and bipolar transurethral resection of prostate transurethral resection using in saline(TUR-IS) system. Eur Urol 2007;52:517-22.

14. Autorino R, Damiano R, Di Lorenzo G, Quarto G, Perdonà S, D’Armiento $\mathrm{M}$, et al. Four-year outcome prospective randomised trial comparing bipolar plasmakinetic and monopolar transurethral resection of prostate. Eur Urol 2009;55:922-31.

15. Mamoulakis C, Skolarikos A, Schulze M, Scoffone CM, Rassweiler JJ, Alivizatos $\mathrm{G}$, et al. Bipolar vs monopolar transurethral resection of the prostate; evaluaiton of the impact on overall sexual function in an international randomized controlled trial setting. BJU Int 2013;112:10920.

16. Karadeniz MS, Bayazit E, Aksoy O, Salviz EA, Tefik T, Sanli O, et al. Bipolar versus monopolar resection of benign prostate hyperplasia:a comparision of plasma electrolytes, hemoglobin and TUR syndrome. Springerplus 2016;5:1739. eCollection 2016.

17. Michielsen DP, Coomans D, Braeckman JG, Umbrain V. Bipolaar transurethral resection in saline ;the solution to avoid hyponatraemia and tranurethral resection syndrome. Scand J Urol Nephrol 2010;44:22835. 